\title{
Research on psychosocial aspects of asthma in the Arab world: a literature review
}

\author{
Anas J Al-khateeb ${ }^{1 *}$ and Jamal M Al khateeb ${ }^{2}$
}

\begin{abstract}
The importance of psychosocial factors in the management of bronchial asthma has long been recognized. This paper offers a review of research published in the English language related to psychosocial aspects of bronchial asthma in Arab countries. Several databases (PubMed, Science Direct, Springer Link, ERIC, and Psychlnfo) were searched using the following keywords: bronchial asthma, Arab countries, Algiers, Bahrain, Comoros, Djibouti, Egypt, Iraq, Jordan, Kuwait, Lebanon, Libya, Mauritania, Morocco, Oman, Palestine (West Bank, Gaza), Qatar, Saudi Arabia, Syria, Tunisia, Sudan, Somalia; United Arab Emirates, and Yemen. Thirty-two studies were conducted in 9 Arab countries. Almost all studies found were published in the last fourteen years with an apparent increasing rate in the last five years. In descending order, these studies addressed: knowledge of and attitudes toward asthma, quality of life, behavioral and emotional problems and factors related to academic achievement.

The main results of the studies reviewed were: (a) physicians', school staff's, and parents' knowledge of and attitudes toward asthma were generally unsatisfactory, (b) in-service asthma education programs significantly impacted parent and staff knowledge and attitudes, and asthma management practices, (c) quality of life in children and adolescents was significantly adversely affected by asthma, (d) asthma was a common cause of school absenteeism, and had a significant negative impact on academic achievement of students, and (e) students with asthma had significantly higher rates of behavioral and emotional difficulties compared to students without asthma. The paper concludes with a discussion about the implications of these results and a call for further research in this area.
\end{abstract}

Keywords: Arab countries, Bronchial asthma, Knowledge, Psychology, Psychosocial aspects, Attitudes, Quality of life

\section{Introduction}

Bronchial asthma, a chronic condition affecting the lungs characterized by widespread, reversible, inflammation and narrowing of the airways [1], is one of the most common non-communicable chronic illnesses among children [2-4]. The incidence of asthma has been on the rise in the past four decades, especially in developed countries[5-7], with more than 300 million people affected worldwide [8].

\section{Review}

It has long been thought that psychological factors may play an important role in bronchial asthma [9-13]. Research published during the last few decades illustrates that psychological disorders are more common in individuals

\footnotetext{
* Correspondence: anas-j-alkhateeb@hotmail.com

'Internal Medicine Department, Saint Michael's Medical Center, 111 Central Avenue, Newark, New Jersey 07102, USA

Full list of author information is available at the end of the article
}

having bronchial asthma, especially if it is poorly controlled $[14,15]$. For instance, children with asthma are more likely than children without asthma to have anxiety and depression [16-19].

Research over the past few decades also indicates that psychological factors may influence the symptoms and management of bronchial asthma in children and adults in many ways [12]. Further, research shows that psychological stress may worsen asthma symptoms [20]. Accordingly, the research literature emphasizes the importance of psychological interventions with children and adults having asthma [21]. Bronchial asthma is one of the leading causes of hospitalization and school absenteeism among school age children [2]. One study [22] reviewed and analyzed empirical studies which examined the relationship between psychosocial factors and asthma management and morbidity in the 1980s and 1990s. This study reported that evidence indicated that psychosocial factors can play an important role in symptom expression and management. 
According to the researcher, caregiver and child mental health attitudes and skills, and problem-solving skills pertaining to asthma management may be among the most important determinants of adherence and subsequent asthma morbidity. However, another study [23] compared psychosocial characteristics of children with asthma and children without asthma. Children's behaviors were assessed by parents with 15 questions. The only significant difference between the two groups was in sleep patterns (children with asthma slept less well than children without asthma). The two groups did not differ significantly in all other items related to school/learning habits, level of activity, and communication/affection. The researchers concluded that psychosocial differences between children with asthma and children without asthma were less remarkable than expected.

A recent bibliometric study of bronchial asthma in Arab countries [24] revealed that before 2000, research on bronchial asthma in Arab countries was low. The Kingdom of Saudi Arabia ranked first among the Arab countries in asthma research, and the majority of this research has been published in English. This study, however, did not provide information on psychosocial aspects of asthma in the Arab region. Rather, it only estimated the contribution of each Arab country in asthma research per year, and grouped studies into ten very general categories (i.e., medicine, immunology and microbiology, pharmacology, biochemistry, and others). To the best knowledge of the authors, no other study reviewed and analyzed asthma research in Arab countries. Accordingly, a study investigating research on psychosocial aspects of asthma in Arab countries is justified.

Thus, the purpose of the present study was to review research on psychosocial aspects of bronchial asthma carried out in Arab countries.

Studies strictly addressing epidemiology, causes and risk-factors, and treatment of asthma were excluded from the current review. First, the methodology used in identifying and reviewing relevant studies is described. Second, the findings are presented and discussed, and implications for future research on the psychosocial aspects of bronchial asthma are offered.

\section{Methods}

Our aim was to review and analyze research related to the psychosocial aspects of bronchial asthma in Arab countries published from 1990-2014 via. The search engines used were: PubMed, PsychINFO, ERIC, SpringerLink, and ScienceDirect. The keywords entered into the search engines were: bronchial asthma, Arab countries, Algiers, Bahrain, Comoros, Djibouti, Egypt, Emirates, Jordan, Iraq, Kuwait, Lebanon, Libya, Mauritania, Morocco, Oman, Palestine (Gaza and West Bank), Qatar,
Saudi Arabia, Somalia, Sudan, Syria, Tunisia, and Yemen. Reference lists at the end of articles located were also viewed in order to find additional articles. The search was restricted to studies published in English language.

\section{Results}

Table 1 shows author(s), country, sample, parameters, and main findings of each study. A total of 32 studies (26 full text articles and 6 abstracts) were found to be relevant for the purpose of this review. These studies were conducted in Egypt $(8 ; 25 \%)$, Jordan $(8 ; 25 \%)$, Saudi Arabia (7; 21.8\%), Qatar (2; 6.3\%), Tunisia (2; 6.3\%), UAE (2; 6.3\%), Bahrain ( $1 ; 3.1 \%)$, Kuwait $(1 ; 3.1 \%)$, and Lebanon $(1 ; 3.1 \%)$. The studies included a total of 71,765 participants (parents, physicians, teachers, and persons with asthma and without asthma of different ages).

Only one study addressed the psychosocial aspects of bronchial asthma in Arab countries before 2000. Twenty (62.5\%) of these studies involved non-probability samples. In descending order, the studies addressed the following topics: knowledge of and attitudes toward asthma, QoL, behavioral and emotional problems and factors related to academic achievement.

All studies used quantitative research methods, collecting data mainly through self-report questionnaires. The main results of the studies reviewed were as follows:

- Physicians', school staff's, and parents' knowledge of and attitudes toward asthma were generally unsatisfactory.

- In-service asthma education programs significantly impacted parent and staff knowledge and attitudes, and asthma management practices.

- QoL in children and adolescents significantly adversely affected by asthma.

- Asthma was a common cause of school absenteeism, and had a significant negative impact on academic achievement of students.

- Students with asthma had significantly higher rates of behavioral and emotional difficulties compared to students without asthma. These difficulties included, but were not limited to: sleep problems, distress, depression, and anxiety.

\section{Discussion}

The present study shows that research on psychosocial aspects of bronchial asthma in the Arab region is quite limited. Despite the increasing number of Arab studies examining psychosocial aspects of bronchial asthma in the Arab world, this type of research remains relatively limited. The average rate of research productivity in this area was about one study per year over the last quartercentury. Only 32 studies were conducted in the 22 countries comprising the Arab world over a period of 
Table 1 An overview of studies on psychosocial aspects of bronchial asthma in Arab countries published in English from year 1990 to 2014

\begin{tabular}{lllll}
\hline Study & & Sample & Parameters & Findings \\
\hline Abdel & Saudi & A random sample of 297 school staff & Knowledge of and attitudes toward & An in-service training program involving \\
Gawwad & Arabia & (225 teachers, 50 administrators, and 22 & asthma, and asthma management & pamphlets and demonstration of inhaler \\
and El- & & social workers) & practices & use significantly impacted staff knowledge, \\
Herishi & & & attitudes, and management practices. \\
$2007[25]$ & & &
\end{tabular}

Abdel Hai Egypt A total of 103 children and adolescents et al. $2010 \quad$ aged between 8 and 16 years [26]

Abudahish Saudi and Bella Arabia 2006 [27]

\section{Al-Akour Jordan A random sample of 326 parents of \\ and 7-17 year-old children with asthma}

Khader

2009 [28]

A random sample of 61 primary health care $(\mathrm{PHC})$ physicians
Al-Akour

and

Khader

2008 [29]

Al-Binali Saudi

et al. 2010 Arabia

[30]
A convenience sample of 171 mothers of children with asthma
Mothers' knowledge and behaviors concerning asthma using an Arab version of the Chicago Community Asthma Survey (CCAS)

Asthma control and QoL as measured by an adapted version of the "Living with Asthma Questionnaire" (LWAQ)

Mean period of school absenteeism

Parents of 1482 schoolboys 141 (9.5\%) of whom were diagnosed with bronchial asthma
Al-Ghamdy Saudi

2000 [33] Arabia

AlGewely Egypt

et al. 2013

[34]
A convenience sample of 606 children (under 13 years of age) with bronchial asthma

A purposefully selected sample of 77 males and 63 females (ages 7-17 years) with bronchial asthma
Socio-clinical profile and impact of bronchial asthma on children's life style

Level of asthma control and QoL as measured by PAQLQ

Teachers' knowledge about bronchial asthma and four other chronic illnesses using a questionnaire
The Arab version of the PAQLQ had high construct and discriminant validity as well as high reliability measured by internal consistency.

PHC physicians' knowledge of and attitudes toward asthma were low. These physicians' practices in asthma care were not satisfactory.

Parents' self-reported QoL was moderate to positive. Parents experienced more limitations in the activities' domain than in the emotions' domain. Parents having older children, living in rural areas, and mothers of children with mild asthma reported higher levels of QoL.

Children's QoL was very low, scoring more limitations in the domain of activities than in emotions and symptoms. QoL of younger, female children, living in rural areas were the lowest.

Mothers lacked the necessary knowledge and practices to care for their children with asthma. Complications of bronchial asthma were the least known by mothers. Significant risk factors for poor knowledge and behaviors among mothers were mother's illiteracy and young age and female sex of the child.

Improved QoL and better control of asthma were reported after the children switched from inhaled corticosteroids to a single inhaler device of Budesonide and/Formoterol.

Mean period of school absenteeism among schoolboys with bronchial asthma was 13.6 compared to 3.7 for classmates without bronchial asthma. School absenteeism among children with bronchial asthma was associated with younger age of children, lower socioeconomic status, history of pets at home, presence of a smoker at home, and hospital visit or admission.

Asthma's adverse effects on children were: sleep problems, school absences, and relatively frequent hospitalization.

QoL was significantly adversely affected by bronchial asthma. Determinants of QoL were: level of asthma control, use of systemic steroids, parental smoking, hospital admission, and difficulties in obtaining drugs.

Teachers' knowledge of bronchia asthma and other chronic illnesses prevailing in local society was 
Table 1 An overview of studies on psychosocial aspects of bronchial asthma in Arab countries published in English from year 1990 to 2014 (Continued)

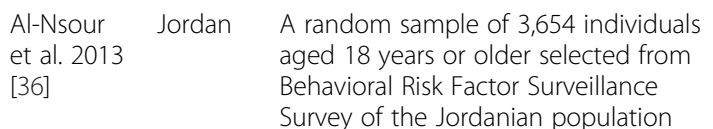
Survey of the Jordanian population 8-18) with bronchial asthma
Jordan A random sample of 261 students (ages
The association between mental distress, bronchial asthma and three other chronic conditions, and adverse health behaviors

Health-related QoL, self-efficacy to resist smoking, and knowledge of asthma selfmanagement

Self-efficacy to resist smoking, asthma knowledge, and QoL students having bronchial asthma who were smokers

A purposefully selected sample of 34 school girls aged 7-11 years with bronchial asthma

A purposefully selected sample of 200 children and adolescents (aged 7-17 years) with bronchial asthma

A convenience sample of 28,447 primary school children aged 6-14 years Feasibility and acceptability of an Arabic
version of a peer-led asthma education
program, and asthma knowledge and
awareness
QoL of children and adolescents with
impaired asthma control and controlled
asthma using the PAQLQ and Arabic
version of the Asthma Control Test
School absenteeism resulting from of children and adolescents with
red asthma control and controlled ired asthma control and controlle

\section{impaired asthma control and contro
asthma using the PAQLQ and Arabic
version of the Asthma Control Test
School absenteeism resulting from
bronchial asthma of the Asthma Control Test
absenteeism resulting from}




\section{Table 1 An overview of studies on psychosocial aspects of bronchial asthma in Arab countries published in English from year 1990 to 2014 (Continued)}

\begin{tabular}{|c|c|c|c|}
\hline $\begin{array}{l}\text { Elkishishy } \\
\& \text { Abu } \\
\text { Hegazy }\end{array}$ & Egypt & $\begin{array}{l}\text { A convenience sample of } 40 \text { adolescents } \\
\text { (aged 13-17 years) with asthma and } 40 \\
\text { adolescents without asthma }\end{array}$ & $\begin{array}{l}\text { Psychological stress, psychopathology } \\
\text { and life satisfaction }\end{array}$ \\
\hline
\end{tabular}

Hegazy

2010 [45]

Fathy et al. Egypt 2014 [46] and healthy controls in anxiety,
A random sample of 50 patients (mean age 28 years) with asthma and 50 patients without asthma (mean age 33 years)

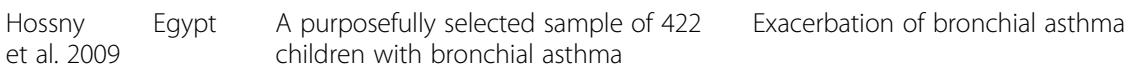

[47]

Kamal \&

Bener 2009

[48]

Kawafha \&

Tawalbeh

2014 [49]

Mansour Egypt et al. 2014 [50]
Qatar

Jordan Questionnaire for Adults (AGKQA) an Arabic version of the Revised
Panicker

et al. 2008

[51]
Kuwait

A sample of 102 patients with asthma and a control group of 102 individuals without asthma aged 20-60 years

\section{Salama Egypt A simple random sample of 352 \\ et al. 2010 \\ [52]}

\begin{tabular}{|c|c|c|}
\hline $\begin{array}{l}\text { Samuel } \\
\text { et al. } 2011 \\
{[53]}\end{array}$ & Egypt & $\begin{array}{l}\text { A convenience sample of } 23 \text { children } \\
\text { with asthma and } 23 \text { children without } \\
\text { asthma with an age range of } 6-15 \text { years }\end{array}$ \\
\hline $\begin{array}{l}\text { Swadi } \\
2001 \text { [54] }\end{array}$ & UAE & $\begin{array}{l}\text { A stratified sample of } 81 \text { students with } \\
\text { bronchial asthma and } 81 \text { students } \\
\text { without asthma with an age range of 6- } \\
13 \text { years }\end{array}$ \\
\hline
\end{tabular}

Zaraket et al. 2011 [55]
Lebanon A convenience sample of 389 parents of children having bronchial asthma aged 3 to 15 years
Zendah Tunisia A convenience sample of 85 adult et al. 2011 [56] persons with asthma
Differences among patients with asthma depression and neuroticism
Compared to adolescents without asthma; adolescents with asthma had more depression, psychopathology, distress and life dissatisfaction.

Both state and trait anxiety were found to be significantly higher in patients with asthma. However, no significant differences were found among participants with and without asthma in depression or neuroticism scores (hysteria; depression; obsession; and somatic, phobic and free-floating anxiety).

Psychological stress was among factors precipitating acute exacerbations of bronchial asthma

Factors associated with school failure

Asthma was the most common chronic disease among students who experienced school failure.

Knowledge about asthma as measured by the Asthma General Knowledge

Cognitive functioning (assessed through Wechsler Intelligence scale for Children (WISC-R), the Auditory Vigilance Test, and the Figural Memory Test) and academic achievement (measured through mid-year test scores in of Arabic and mathematics subjects)

Psychological distress in patients with bronchial asthma as measured by the World Health Organization (WHO) - Five Well-Being Index

Physicians' knowledge, practices and attitudes toward and adherence to national and international asthma management guidelines assessed by a self-administered questionnaire

The asthma education program significantly improved the experimental group's knowledge of asthma.

Bronchial asthma had a significant negative impact on academic achievement and cognitive functioning of students with bronchial asthma.

Patients with asthma were significantly more psychologically distressed than the control group. The level of psychological distress was significantly higher among younger, female patients with shorter duration of asthma.

Physicians' had poor knowledge and attitudes. About $25 \%$ of the studied physicians were not in agreement with the guidelines claiming that their disagreement was mainly due to patient factors (poor socioeconomic standards and poor patient compliance).

Intellectual functioning and psychosocial Cognitive abilities, psychosocial adjustment as measured by WISC-R and Pediatric Symptom Checklist (PSCL)

Behavioral and emotional problems assessed by an Arabic version of Rutter Children Behavior Questionnaire (parents' and teachers' versions)

adjustment and academic achievement were negatively influenced by bronchial asthma.

Students with asthma were reported to have significantly higher rates of behavioral and emotional difficulties compared to students without asthma.

Parental perceptions and beliefs about childhood asthma and its management

Parents of children with asthma showed fear of social stigma and harbored considerable misperceptions about the disease. It was also found that asthma was an important cause for school absence.

QoL as measured by Juniper's Quality of Factors that negatively affect QOL were: Life Scale the intellectual level, asthma severity and the absence of treatment adjustment. 
24 years. Likewise, only few psychological factors were addressed in these studies. Nonetheless, these studies shed light on some psychological factors that influence the quality of life, academic achievement, and behavioral and emotional development of children and adolescents with asthma in Arab countries.

One main result reported by the studies reviewed here was that physicians', school staff's, and parents' knowledge of and attitudes toward asthma were generally unsatisfactory. Similar findings were reported by researchers in other countries. For instance, primary school teachers in Turkey lacked knowledge on triggers of asthma attacks and on the management of this disease [57]. In the USA, studies have revealed that lack of education for nurses, parents, and physicians were among major barriers to asthma management in schools [58]. In China, it was reported that the parents' knowledge of asthma was generally poor [59].

It was also reported by studies reviewed that in-service asthma education programs significantly impacted knowledge and attitudes, and asthma management practices. This result is in agreement with those of many studies conducted in other countries showing that training courses could have a positive impact on asthma control [60] and that education programs pertaining to application of standard treatment guidelines improved asthma control [61].

Another main result reported by the studies reviewed was that quality of life in children and adolescents was significantly adversely affected by asthma. This finding is consistent with those of previous non-Arab studies which have shown that children having asthma generally tend to have lower levels of quality of life than children without asthma [62-64] and that quality of life decreased with increasing asthma severity [65]. Further, studies included in this review showed that asthma was a common cause of school absenteeism, and had a significant negative impact on academic achievement of students. Similar findings were reported in other countries $[66,67]$. Finally, a main finding in this review was that children and adolescents with asthma had significantly higher rates of behavioral and emotional difficulties compared to children and adolescents without asthma. Similar findings were reported by many researchers in other countries [68-70].

While published studies provided beneficial insights into psychological factors associated with bronchial asthma in Arab countries, much research remains to be conducted. Research in Arab countries has not yet addressed many important psychological issues related to bronchial asthma. For instance, very few studies analyzed in this review attempted to utilize psychological interventions (e.g., cognitive behavioral therapy, behavioral therapies, relaxation techniques) to increase the effectiveness of asthma management and treatment through procedures such as promoting adherence and asthma control, managing emotional triggers, adopting appropriate adjustment and coping styles, and improving knowledge and attitudes, among others. No study explored the relationship between asthma and the individual's personality. Further, research on psychosocial aspects of asthma was conducted in only 9 out of 22 countries comprising the Arab world.

The research literature advocates a multidisciplinary or team approach to management of bronchial asthma $[71,72]$. This approach which may involve such services as patient education, self-management, counseling and nutritional advice has been shown to improve quality of life and to reduce exacerbations and hospitalizations in patients with asthma $[73,74]$. The studies reviewed in the current review, however, revealed that this type of research is lacking in the Arab world. Accordingly, the need for further multidisciplinary research on the role of psychological factors in asthma management in Arab countries is clear. In addition, the program curricula in medical schools in the Arab world probably need to increase students' awareness of psychological and behavioral aspects of illness, particularly chronic diseases having emotional components such as bronchial asthma. As Cuff and Vanselow [75] stated, measurable improvements in the health of individuals is unlikely to be achieved unless physicians are "equipped with the knowledge and skills from the behavioral and social sciences needed to recognize, understand, and effectively respond to patients as individuals, not just to their symptoms" (p. 3).

There is also a clear need for research addressing the potential effects of political and social turbulences on health status and care of individuals, including those with chronic illnesses such as bronchial asthma, in present-day Arab world. It is believed that "the psychological distress resulting from repetitive exposure to extreme forms of psychological trauma has put millions of civilians in the Middle East at high risk for traumarelated psychopathology" [76]. The "Arab Spring" which has touched many Arab countries recently may have significant consequences for population health. The violence and upheaval have resulted in significant political and economic challenges; difficult post-war conditions including influx of refugees throughout the region; under-employment and subsequent draining of financial, social, and health resources [77-79]. Another aspect that could affect health problems like asthma during "Arab Spring" is having high levels of psychological stress [76], a known serious trigger of asthma [80]. In a longitudinal cohort study [81] which investigated the role of psychological stress in the etiology of asthma, a strong association was found between stress and asthma incidence 
and hospitalization, use of asthma medication as well as with allergic rhinitis and atopic dermatitis in adults.

In addition, asthma is associated with environmental factors that can be increased during social unrest and civil wars, via means of fire, smoke, dust, and other toxic chemicals. Such events will not only have immediate impact, but can also have long-term effects. This has been illustrated in follow up studies $[82,83]$ of the World Trade Center rescue and recovery workers which showed persistence of health problems such as asthma, sinusitis, gastroesophageal reflux disease, depression, post-traumatic stress disorder, and panic attacks.

As mentioned previously, the majority of studies reviewed used self-report questionnaires to collect data from participants. It is well known that self-reports are subject to various sources of inaccuracies. Two major theoretical perspectives explain validity problems in some self-reported data [84]. The first is the cognitive perspective which attributes validity problems to inaccuracies arising from comprehension and recall. The second is the situational perspective which focuses on validity problems that arise from factors related to social desirability and interviewing conditions. Also, all studies reviewed used quantitative research methods in investigating the psychosocial aspects of bronchial asthma. However, research using qualitative methods such as indepth interviews, case studies and participant observations [85] can yield important information by reflecting the experiences and stories of children and adolescents with bronchial asthma.

The present study has some limitations that need to be considered when interpreting the findings. First, this review was restricted to studies published in English and to studies published in referred journal articles. However, there may be studies published in Arabic or French (especially by researchers from Lebanon, Tunisia, Morocco, Algiers where French is widely spoken) or published as conference papers, master or doctoral theses, book chapters, etc. In addition, the studies originated from only 9 out of 22 Arab countries. These countries are quite diverse not only in terms of religion, history, economics, and politics but also in living standards and health care services. Finally, many studies reviewed involved non-probability or small samples. Therefore, caution should be exercised in making generalizations about psychosocial aspects of bronchial asthma in Arab countries.

\section{Conclusions}

Research literature in Arab countries is lacking in quality studies investigating the psychosocial aspects of bronchial asthma. There have recently been some attempts to explore this research area; nonetheless, most studies carried out so far have investigated few psychological factors related to asthma. Further research involving randomized multicenter studies and using more rigorous research methods are needed to better understand the psychosocial aspects of bronchial asthma in the Arab world.

\section{Abbreviations \\ QoL: Quality of Life; UAE: United Arab Emirates; PAQLQ: Pediatric Asthma Quality of Life Questionnaire; PHC: Primary Health Care; CCAS: Chicago Community Asthma Survey; LWAQ: Living with Asthma Questionnaire; AGKQA: Asthma General Knowledge Questionnaire for Adults; WISC-R: Wechsler Intelligence scale for Children; WHO: World Health Organization; PSCL: Pediatric Symptom Checklist}

\section{Competing interests}

The authors declare that they have no competing interests.

\section{Authors' contributions}

Both authors were involved in drafting the article, and both approved the final version to be submitted for publication.

\section{Authors' information}

Anas J. Al-khateeb, M.D. graduated from the Faculty of Medicine, the University of Jordan, Amman-Jordan. He worked as a resident at King Hussein Cancer Medical Center for one year. He is currently a senior resident at the Department of Internal medicine, Saint Michael's Medical Center, Newark, NJ, USA

Jamal M. Al khateeb, is a professor of special education at Counseling \& Special Education Department, College of Educational Sciences, the University of Jordan, Amman, Jordan. He has published extensively on issues related to disability and rehabilitation in the Arab world.

\section{Author details}

${ }^{1}$ Internal Medicine Department, Saint Michael's Medical Center, 111 Central Avenue, Newark, New Jersey 07102, USA. ${ }^{2}$ Department of Counseling \& Special Education, College of Education, University of Jordan, Queen Rania Street, Amman 119942, Jordan.

Received: 19 February 2015 Accepted: 17 March 2015

Published online: 15 April 2015

\section{References}

1. Peters TE, Fritz GK. Psychological considerations of the child with asthma. Pediatr Clin. 2011;58(4):921-35.

2. American Lung Association. Asthma and children fact sheet. Retrieved from www.lung.org; 2014

3. Bousquet J, Bousquet PJ, Godard P, Daures JP. The public health implications of asthma. Bull World Health Organ. 2005;83:548-54.

4. Manning PJ, Goodman P, O'Sullivan A, Clancy L. Rising prevalence of asthma but declining wheeze in teenagers (1995-2003): ISAAC protocol. Ir Med J. 2007;100:614-5

5. Ananden C, Nurmatov U, van Schayk OCP, Sheikh A. Is the prevalence of asthma declining? Systematic review of epidemiological studies. Allergy. 2010;65(2):152-67.

6. Asher MI, Montefort S, Bjorksten B, Lai CK, Strachan DP, Weiland SK, et al. Worldwide time trends in the prevalence of symptoms of asthma, allergic rhinoconjunctivitis, and eczema in childhood: ISAAC Phases One and Three repeat multicountry cross-sectional surveys. Lancet. 2006;368:733-43.

7. Bahadori K, Doyle-Wters MM, Marra C, Lynd L, Alasaly K, Swiston J, et al. Economic burden of asthma: a systematic review. BMC Pulm Med. 2009;9:24.

8. Bener A, Ehlayel MS, Bener HZ. Association between asthma and attention-deficit hyperactivity disorders in children: Potential risk factors. Indian J Allergy Asthma Immunol. 2014:28:19-26.

9. Bloomberg GR, Chen E. The relationship of psychologic stress with childhood asthma. Immunol Allergy Clin N Am. 2005:25:83-105.

10. Campbell DA, McLennan G, Coates JR, Frith PA, Gluyas PA, Latimer KM et al. A comparison of asthma deaths and near-fatal asthma attacks in South Australia. Eur Respir J. 1994;7:490-7.

11. Harrison BDW. Psychosocial aspects of asthma in adults. Thorax. 1998:53:519-25. 
12. van Lieshout RVJ, MacQueen G. Psychological factors in asthma. Allergy Asthma Clin Immunol. 2008:4(1):12-28.

13. Gordon R, Bloomberg GR, Edith C. The relationship of psychological stress with childhood asthma. Immunol Allergy Clin. 2005;25:83-105.

14. Boulet LP, Boulay ME. Asthma-related comorbidities. Expert Rev Respir Med. 2011;5(3):377-93.

15. Kewalramani A, Bollinger ME, Posolache $\Pi$. Asthma and mood disorders Int J Child Health Hum Dev. 2008;1(2):115-23.

16. Barton C, Clarke D, Sulaiman N, Abramson M. Coping as a mediator of psychological impediments to optimal management and control of asthma. Respir Med. 2003;97:747-61.

17. Moussas G, Tselebis A, Karkanias A, Stamouli D, llias I, Bratis D. A comparative study of anxiety and depression in patients with bronchial asthma, chronic obstructive pulmonary disease and tuberculosis in a general hospital of chest diseases. Ann Gen Psychiatr. 2008;7:7.

18. Moussavi S, Chatterji S, Verdes E, Tandon A, Patel V, Ustun B. Depression, chronic diseases, and decrements in health: Results from the World Health Surveys. The Lancet. 2007;370:851-8.

19. Reed MG, Adolf D, Werwick K, Herrmann M. Knowledge and attitudes of GPs in Saxony Anhalt concerning the psychological aspects of bronchial asthma: A questionnaire study. BioPsychoSocial Med. 2010;4(23):2-8.

20. Chen E, Miller GE. Stress and inflammation in exacerbations of asthma. Brain Behav Immun. 2007;21(8):993-9.

21. Yorke J, Fleming SL, Shuldham C. Psychological interventions for adults with asthma: A systematic review. Respir Med. 2007;101(1):1-14.

22. Wade SL. Psychosocial components of asthma management in children. Dis Manag Health Outcome. 2000;8(1):17-27.

23. Wjst M, Roell G, Dold S, Wulff A, Reitmeir P, Fritzsch C, et al. Psychosocial characteristics of asthma. J Clin Epidemiol. 1996:49(4):461-6.

24. Sweileh WM, Al-Jabi SW, Zyoud SH, Sawalha AF. Bronchial asthma and chronic obstructive pulmonary disease: research activity in Arab countries. Multidiscip Resp Med. 2014:9:38

25. Abdel Gawwad ES, El-Herishi S. Asthma education for school staff in Riyadh city: Effectiveness of pamphlets as an educational tool. J Egypt Public Health Assoc. 2007;82(1-2):147-71.

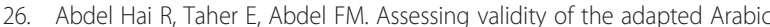
Pediatric Asthma Quality of Life Questionnaire among Egyptian children with asthma. East Mediterr Health J. 2010;16(3):274-80.

27. Abudahish A, Bella H. Primary care physicians perceptions and practices on asthma care in Aseer region, Saudi Arabia. Saudi Med J. 2006;27:333-7

28. Al-Akour N, Khader YS. Having a child with asthma: Quality of life for Jordanian parents. Int J Nurs Pract. 2009;15(6):574-9.

29. Al-Akour N, Khader YS. Quality of life in Jordanian children with asthma. Int J Nurs Pract. 2008;14(6):418-26.

30. Al-Binali AM, Mahfouz AA, Al-Fifi S, Naser SM, Al-Gelban KS. Asthma knowledge and behaviors among mothers of asthmatic children in Aseer, south-west Saud Arabia. East Mediterr Health J. 2010;16:1153-8.

31. Albsoul-Younes AM, Al-Doghim IA, Al-Safi SA, Najada AS. Improving quality of life in asthmatic children. Indian J Pediatr. 2004;71(12):1075-8.

32. Al-Dawood KM. Schoolboys with bronchial asthma in Al-khobar City, Saudi Arabia: Are they at increased risk of school absenteeism? J Asthma. 2002;39:413-20.

33. Al-Ghamdy YS, Al-Haddad NS, Adelgadir MH, Qureshi NA, Saleh MA, Khalil MM. Socioclinical profile of children with asthma in Al-Majmaah Health Province. Saudi Med J. 2000;21(9):847-51.

34. AlGewely MS, El-Hosseiny M, Abou Elezz NF, ElGhoneimy DH, Azza M, Hassan AM. Health-related quality of life in childhood bronchial asthma. Egypt J Pediatr Allergy Immunol. 2013;11(2):83-93.

35. Alnasir FA, Skerman JH. Schoolteachers' knowledge of common health problems in Bahrain. East Mediterr Health J. 2004;10(4-5):537-46.

36. Al-Nsour M, Zindah M, Belbeis IA, Rolle IV, Walke $H$, Strine T, et al. Frequent mental distress, chronic conditions, and adverse health behaviors in the Behavioral Risk Factor Surveillance Survey, Jordan, 2007. Prev Chronic Dis. 2013;22; 10:e140

37. Al-sheyab N, Gallagher R, Crisp J, Shah S. Peer-led education for adolescents with asthma in Jordan: A cluster-randomized controlled trial. Pediatrics. 2012;129:e106-12.

38. Al-Shayeb N, Gallagher R, Gallagher P, Shah S. Cigarette smoking in adolescents with asthma in Jordan: Impact of peer-led education in high schools. J Nurs Educ Pract. 2013;3(9):13-22
39. Al-Sheyab NA, Gallagher R, Roydhouse JK, Crisp J, Shah S. Feasibility of a peer-led, school-based asthma education program for adolescents in Jordan. East Mediterr Health J. 2012;18(5):468-73.

40. Al Zahrani SS, El Morsy EA, Laila S, Dorgham LS. The impact of bronchial asthma on quality of life among affected children and adolescents in Taif city, Saudi Arabia. Life Sci J. 2014;11(6):283-91.

41. Bener A, Abdulrazzaq YM, Dubuse P, Abdin AH. Asthma and wheezing as the cause of school absence. J Asthma. 1994:31:93-8.

42. Bener A, Shanks NJ, Kamal M. Impact of asthma and air pollution on school attendance of primary school children: are they at increased risk of school absenteeism? J Asthma. 2007:44(4):249-52.

43. Benzarti M, Mezghanni S, Jerray M, Garrouche A, Hayouni A. The quality of life in a Tunisian population of asthmatic patients. Tunis Med. 2003;81(5):308-17.

44. Binsaeed AA, Torchyan AA, Alsadhan AA, Almidani GM, Alsubaie AA, Aldakhail AA, et al. Determinants of asthma control among children in Saudi Arabia. J Asthma. 2014;51:435-9.

45. Elkishishy HI, Abu HH. Psychopathology, psychological stress and life satisfaction among sample of female adolescents with bronchial asthma. Curr Psychiatr. 2010;17(2):7-15.

46. Fathy A, Abd Algawad T, Arram E, Elboraei H, Arafat M, Elmetwaly S. Neuroticism, anxiety, and depression in Egyptian atopic bronchial asthma. Egypt J Dis Chest Tubercul. 2014;63(2):299-303.

47. Hossny EM, Hasan ZE, Allam MF, Mahmoud ES. Analysis of the filed data of a sample of Egyptian children with bronchial asthma. Egypt J Pediatr Allergy Immunol. 2009;7(2):59-64.

48. Kamal M, Bener A. Factors contributing to school failure among school children in very fast developing Arabian Society. Oman Med J. 2009;24 (3):212-7.

49. Kawafha MM, Tawalbeh LI. The effect of asthma education program on knowledge of school teachers: A randomized controlled trial. Western J Nurs Res. 2014;36(3) [Epub ahead of print]

50. Mansour AE, Yasein YA, Ghandour A, Zaidan O, Abo E-AM. Prevalence of bronchial asthma and its impact on the cognitive functions and academic achievement among preparatory school children in Damietta governorate. Egypt J Am Sci. 2014;10(7):119-27

51. Panicker NR, Sharma PN, Al-Duwaisan AR. Psychological distress and associated risk factors in bronchial asthma patients in Kuwait. Indian J Med Sci. 2008:62(1):1-7.

52. Salama AA, Mohammed AA, EE E O, Said RM. Quality of care of Egyptian asthmatic children: Clinicians' adherence to asthma guidelines. Ital J Pediatr. 2010;36:33.

53. Samuel S, Sawfwat M, Morcos W, Salem S, Al-Adly T, Mohammad A. Chronic asthmatic chest troubles and their effects on cognitive functions, psychosocial behavior and academic achievement among children in Egypt. Am J Sci. 2011;7(1):400-6.

54. Swadi H. Psychiatric morbidity in a community sample of Arab children with asthma. J Trop Pediatr. 2001;47(2):106-7.

55. Zaraket R, Al-Tannir MA, Bin Abdulhak AA, Shatila A, Lababidi H. Parental perceptions and beliefs about childhood asthma: A cross-sectional study. Croat Med J. 2011;52(5):637-43

56. Zendah I, Cherif R, Khattab A, Ghedira H. Assessment of quality of life in asthmatics in Tunisia: A prospective study of 85 cases. Tunis Med. 2011:89(2):179-83.

57. Ones U, Akcay A, Tamay Z, Guler N, Dogru M. Asthma knowledge level of primary schoolteachers in Istanbul, Turkey. Asian Pac J Allergy Immunol. 2006;24(1):9-15.

58. Major DA, Clarke SM, Cardenas RA, Taylor-Fishwick JC, Kelly CS, Butterfoss FD. Providing asthma care in elementary schools: Understanding barriers to determine best practices. Fam Community Health. 2006;29(4):256-65.

59. Zhao J, Shen K, Xiang L, Zhang G, Xie M, Bai J, et al. The knowledge, attitudes and practices of parents of children with asthma in 29 cities of China: A multi-center study. BMC Pediatr. 2013;13:20.

60. Kotwani A, Chhabra SK. Effect of patient education and standard treatment guidelines on asthma control: An intervention trial. WHO South-East Asia Journal of Public Health. 2012;1(1):42-51.

61. Urek MC, Tudoric N, Plavec D, Urek R, Koprivc-Milenovic T, Stojic M. Effect of educational programs on asthma control and quality of life in adult asthma patients. Patient Educ Couns. 2005;58(1):47-54

62. Goldbeck L, Koffmane K, Lecheler J, Thiessen K, Fegert JM. Disease severity, mental health, and quality of life of children and adolescents with asthma. Pediatr Pulmonol. 2007;42(1):15-22. 
63. Hallstrand TS, Curtis JR, Aitken ML, Sullivan SD. Quality of life in adolescents with mild asthma. Pediatr Pulmonol. 2003;36(6):536-43.

64. Merikallio VJ, Mustalahti K, Remes ST, Valovirta EJ, Kaila M. Comparison of quality of life between asthmatic and healthy school children. Pediatr Allergy Immunol. 2005;16(4):332-40.

65. Warschburger P, Busch S, Bauer CP, Kiosz D, Stachow R, Petermann F. Health-related quality of life in children and adolescents with asthma: Results from the ESTAR Study. J Asthma. 2004;41(4):463-70.

66. Krenitsky-Korn S. High school students with asthma: attitudes about school health, absenteeism, and its impact on academic achievement. Pediatr Nurs. 2011;37(2):61-8.

67. Moonie S, Sterling DA, Figgs LW, Castro M. The relationship between school absence, academic performance, and asthma status. J Sch Health 2008;78(3):140-8

68. Blackman JA, Gurka MJ. Developmental and behavioral comorbidities of asthma in children. J Dev Behav Pediatr. 2007;28(2):92-9.

69. Klinnert MD, McQuaid EL, McCormick D, Adinoff AD, Bryant NE. A multimethod assessment of behavioral and emotional adjustment in children with asthma. J Pediatr Psychol. 2000;25(1):35-46.

70. Bussing R, Halfon N, Benjamin B, Wells KB. Prevalence of behavior problems in US children with asthma. Arch Pediatr Adolesc Med. 1995:149(5):565-72.

71. van Eeden SF, Burns J. A multidisciplinary approach to the treatment and management of chronic obstructive pulmonary disease. BCMJ. 2008;50(3):143-7.

72. Wright RJ, Rodriguez M, Cohen S. Review of psychosocial stress and asthma: an integrated biopsychosocial approach. Thorax. 1998;53(12):1066-74.

73. Clark NM, Griffiths C, Keteyian SR, Partridge MR. Educational and behavioral interventions for asthma: Who achieves which outcomes? A systematic review. J Asthma Allergy. 2010;3:187-97.

74. Hart MK, Millard MW. Approaches to chronic disease management for asthma and chronic obstructive pulmonary disease: strategies through the continuum of care. Proc (Bayl Univ Med Cent). 2010;23(3):223-9.

75. Cuff PA, Vanselow N. Improving medical education: Enhancing the behavioral and social science content of medical school curricula. Washington: National Academic Press; 2004.

76. Neria U, Bravova M, Halper JM. Trauma and PTSD among civilians in the Middle East. PTSD Research Quarterly. 2010;21(4):1-8.

77. Al-Khateeb JM, Al-Khateeb AJ. Research on psychosocial aspects of epilepsy in Arab countries: A review of literature. Epilepsy Behav. 2014;31:256-62.

78. Amawi N, Mollica RF, Lavelle J, Osman O, Nasir L. Overview of research on the mental health impact of violence in the Middle East in light of the Arab Spring. J Nerv Ment Dis. 2014;202(9):625-9.

79. Coutts A, Stuckler D, Batniji R, Ismail S, Maziak W, McKee M. The Arab Spring and health: Two years on. Int J Health Serv. 2013;43(1):49-60.

80. Lehrer P, Feldman J, Giardino N, Song HS, Schmaling K. Psychological aspects of asthma. J Consult Clin Psychol. 2002;70(3):691-711.

81. Rod NH, Kristensen TS, Lange P, Prescott E, Diderichsen F. Perceived stress and risk of adult-onset asthma and other atopic disorders: A longitudinal cohort study. Allergy. 2012;67(11):1408-14.

82. Potera C. Disaster response: Mental health effects among WTC rescue and recovery workers. Environ Health Perspect. 2008;116(9):A395.

83. Wisnivesky JP, Teitelbaum SL, Todd AC, Boffetta P, Crane M, Crowley L, et al. Persistence of multiple illnesses in World Trade Center rescue and recovery workers. Lancet. 2011;378(9794):888-97.

84. Bener ND, Billy JO, Grady WR. Assessment of factors affecting the validity of self-reported health-risk behavior among adolescents: Evidence from the scientific literature. J Adolesc Health. 2003;33(6):436-57.

85. Johnson JB, Christensen L. Educational research: Quantitative, qualitative, and mixed approaches. Thousand Oaks, CA: Sage Publications; 2008

\section{Submit your next manuscript to BioMed Central and take full advantage of:}

- Convenient online submission

- Thorough peer review

- No space constraints or color figure charges

- Immediate publication on acceptance

- Inclusion in PubMed, CAS, Scopus and Google Scholar

- Research which is freely available for redistribution

Submit your manuscript at www.biomedcentral.com/submit 